\title{
Platelet Rich Plasma Promotes Proliferation of Adipose Derived Mesenchymal Stem Cells via Activation of AKT and Smad2 Signaling Pathways
}

Fatemeh Atashi ${ }^{1}$, Véronique Serre-Beinier ${ }^{2}$, Zeynab Nayernia ${ }^{3}$, Brigitte Pittet-Cuénod ${ }^{1}$ and Ali Modarressi ${ }^{1 *}$

${ }^{1}$ Department of Plastic, Reconstructive and Aesthetic Surgery, University Hospitals of Geneva, Faculty of Medicine, Geneva University, Geneva, Switzerland ${ }^{2}$ Department of Thoracic Surgery, University Hospitals of Geneva, Faculty of Medicine, Geneva University, Geneva, Switzerland ${ }^{3}$ Department of Pathology and Immunology, Faculty of Medicine, Geneva University, Geneva, Switzerland

\begin{abstract}
Recently, autologous platelet-rich plasma (PRP) has been proposed as a substitute for xenogenic or allogenic culture media used for in vitro cell expansion. Although PRP has been demonstrated to promote adipose-derived mesenchymal stem cell (ASC) expansion, its mechanism of action has not yet been investigated. In this study, we aimed to assess the growth factors and molecular pathways implicated in enhancement of ASC proliferation by PRP.
\end{abstract}

Cell proliferation was analyzed in ASCs cultured for 10 days with $20 \%$ autologous PRP and compared to those supplemented with $10 \%$ fetal bovine serum (FBS). The secretion of PDGF-AB, FGF, TGF $\beta$, VEGF, and MIF in the culture media was investigated. In addition, AKT, ERK, and Smad2 signalling pathway activation involved in ASC proliferation was assessed using western blot analysis.

The expansion rate of cultured ASCs was 14 times greater with 20\% PRP than with 10\% FBS. Proliferation rate of ASCs was higher in $20 \%$ PRP-supplemented medium than in $10 \%$ FBS. PDGF-AB, FGF, TGF $\beta$, and VEGF were present in the medium supplemented with $20 \%$ PRP up to 10 days. Macrophage migration inhibitory factor (MIF) secretion was confirmed in both media, and a higher level was seen in $20 \%$ PRP. The AKT, ERK and Smad2 signalling pathways were more activated in ASCs cultured with PRP compared to FBS.

In summary, our results indicate that PRP regulates ASC proliferation through secreted proteins (PDGF-AB, FGF, TGF $\beta$, VEGF, and MIF). Growth factor/receptor complexes activate mainly AKT and Smad2 and to a lesser extent, ERK signalling pathways.

Keywords: Adipose-derived mesenchymal stem cells; Platelet-rich plasma; Macrophage migration inhibitory factor (MIF); Growth factor; Proliferation; AKT; Smad2; ERK1/2

\section{Introduction}

Adipose-derived mesenchymal stem cells (ASCs) are multipotent cells that have the ability to self-renew. They are promising candidates for gene and cell therapy because they have great differentiating potential to mesodermal lineage such as adipocyte, chondrocyte, and osteocyte [1-3], and even into endoderm and ectoderm cells [4,5].

Clinical applications of ASCs often require extensive in vitro cell expansion, and the culture media should be safe, biocompatible, and efficient without modifying cell phenotype or differentiation capacity. Thus far, ASCs have been studied mostly using animal-derived products such as fetal bovine serum (FBS) or allogenic additives (e.g., human serum or human platelet derivatives) as the media supplement [6-9]. However, these non-autologous supplements present some disadvantages such as infection or immunological reaction risks, limited efficiency, and high cost that limit their clinical use [10]. Therefore, the use of autologous blood-derived supplements platelet-rich plasma (PRP) has gained recent interest $[11,12]$. We have previously demonstrated that autologous PRP significantly enhances ASC proliferation without influencing cell characteristics [12]. PRP contains live platelets able to continually secrete various mitogenic proteins (e.g., growth factors and cytokines) for more than 10 days in cell culture [12]. Among platelet mitogenic proteins, platelet derived growth factor (PDGF-AB), transforming growth factor (TGF $\beta$ ), fibroblast growth factor (FGF), vascular endothelial growth factor (VEGF) and macrophage migration inhibitory factor (MIF) are thought to be the most involved during in vitro cell expansion [13].
Macrophage migration inhibitory factor (MIF) is a $12 \mathrm{kDa}$ proinflammatory cytokine known as a regulator of inflammation and immune response [14] and is released mainly by white blood cells when stimulated by bacterial antigens [15]. It is also ubiquitously expressed in various cells and tissues such as pancreatic beta-cells, liver and adipocytes [16,17]. It is known that ASCs [18] and platelets [19] also express MIF upon inflammatory and stress stimulation [20]. ASCs express MIF intracellularly when stimulated. MIF is known to regulate cell proliferation [21-24], migration [17], and differentiation [25]. Addition of recombinant (exogenous) MIF increases proliferation of many cell types such as stromal or progenitor neural cells, fibroblasts, smooth muscle cells, epithelial cells, and even MSCs [21-24]. It is known that both endogenous and exogenous MIF activate AKT signalling, delay cellular senescence, and promote cellular multipotency associated markers in MSCs [26].

${ }^{*}$ Corresponding author: Ali Modarressi, MD, Division of Plastic, Reconstructive \& Aesthetic Surgery, University Hospitals of Geneva, Rue Gabrielle-Perret-Gentil $4 \mathrm{CH}-1211$, Geneva, Switzerland, Tel: +41-22-3728003; Fax: +41-22-3728005; E-mail: ali.modarressi@hcuge.ch

Received August 12, 2015; Accepted August 29, 2015; Published August 31, 2015

Citation: Atashi F, Serre-Beinier V, Nayernia Z, Pittet-Cuénod B, Modarress A (2015) Platelet Rich Plasma Promotes Proliferation of Adipose Derived Mesenchymal Stem Cells via Activation of AKT and Smad2 Signaling Pathways. J Stem Cell Res Ther 5: 301. doi:10.4172/2157-7633.1000301

Copyright: ( 2015 Atashi F, et al. This is an open-access article distributed under the terms of the Creative Commons Attribution License, which permits unrestricted use, distribution, and reproduction in any medium, provided the original author and source are credited. 
Citation: Atashi F, Serre-Beinier V, Nayernia Z, Pittet-Cuénod B, Modarressi A (2015) Platelet Rich Plasma Promotes Proliferation of Adipose Derived Mesenchymal Stem Cells via Activation of AKT and Smad2 Signaling Pathways. J Stem Cell Res Ther 5: 301. doi:10.4172/21577633.1000301

Page 2 of 10

Binding of PDGF-AB and VEGF to PDGF receptors (PDGFR) [27-29], TGF $\beta$ to TGF $\beta$ receptors I and II (TGF $\beta R$ I, II), EGF to EGF receptors (EGFR), FGF to FGF receptors (FGFR) [30], and MIF to MIF receptors (CD74, CXCR2, CXCR4) [31] triggers several downstream cascades. Mitogen-activated protein kinase (MAPK), extracellular signal regulated kinase [7], the phosphatidylinositol 3-kinase PI3K/ AKT and Smad $2 / 3$ are the main signalling pathways involved in ASC proliferation $[29,32,33]$.

However, the link between growth factors present in PRP and proliferation of ASCs has not yet been investigated. Understanding their mechanisms of action and their pathways of controlling ASC destiny would be valuable for conducting tissue-engineering approaches both in vitro and in vivo. In this study, we focused on the primary signaling cascades that could potentially be involved in enhancing ASC proliferation. We assessed cell proliferation rate by measuring proliferating cell nuclear antigen (PCNA), which is essential for DNA synthesis [34]. We further investigated the link between proliferation and alterations in the G1/S checkpoint of the cell cycle by assessing expression level of cyclin D1, a protein, which is expressed during cell proliferation. We aimed to investigate the growth factors secreted by live platelets presented in culture media supplemented with PRP as well as their primary signalling pathways involved in ASC proliferation.

\section{Materials and Methods}

\section{Fat tissue harvesting and ASC isolation}

Adipose tissue was collected and purified from the subcutaneous abdomen layer of three consenting patients as described by Coleman [35]. Briefly, $30 \mathrm{~mL}$ fat tissue was manually harvested from patients who underwent abdominoplasty with a $3 \mathrm{~mm}$ cannula (Mentor, Santa Barbara, CA) connected to $10 \mathrm{~mL}$ Luer-Lok syringes (BD Biosciences, Franklin Lakes, NJ). The isolated fat tissue was purified from blood, oil, and liquid after 3 min centrifugation at $1200 \mathrm{~g}$. As previously described [12], to isolate ASCs, the adipose tissue was then digested with $0.01 \%$ collagenase type I (Sigma-Aldrich, St. Louis, MO) for 30 to $45 \mathrm{~min}$ at $37^{\circ} \mathrm{C}$ with gentle agitation. After $10 \mathrm{~min}$ centrifugation at 500 $\mathrm{g}$, the remaining pellet, known as the stromal vascular fraction (SVF), was suspended in erythrocyte lysis buffer for 5 min (Qiagen, Hilden, Germany) and then washed with the basal medium, Dulbecco's modified Eagle's medium (DMEM; Life technologies), and supplemented with penicillin and streptomycin (10,000 mg/mL; Bioconcept, Salem, NH) and 2 units/mL heparin (Liquemin 5000; Roche, Basel, Switzerland). After centrifugation at $226 \mathrm{~g}$ for $5 \mathrm{~min}$, the SVF was then resuspended in DMEM with supplements and filtered through a $100-\mathrm{mm}$ nylon cell strainer (BD Biosciences). The mean cell density in the isolated SVF was $30 \times 10^{4} \mathrm{cells} / \mathrm{ml}$.

\section{PRP preparation}

PRP was prepared using specific tubes containing $1 \mathrm{~mL}$ sodium citrate as an anticoagulant and a specific gel for separating platelets and plasma from other blood components (e.g., red and white blood cells) from three patients as described previously [12]. Briefly, $8 \mathrm{~mL}$ of peripheral blood was collected from each patient into a Regen-BCT tube (Regen Kit; RegenLab, Le Mont-sur-Lausanne, Switzerland). To keep the technique completely autologous, for each experiment the blood donor was the same as the fat donor. The collected blood was centrifuged in a standard laboratory centrifuge for $5 \mathrm{~min}$ at $1500 \mathrm{~g}$. Hence, the plasma and platelets were accumulated above the gel layer whereas the white and red blood cells were collected in the bottom of the tube under the separator gel. Plasma containing a high yield of platelets was homogenized by turning up and down the tube five times to obtain $4 \mathrm{~mL}$ PRP.

\section{ASC culture}

Cells from the SVF were plated at $2500 \mathrm{cell} / \mathrm{cm}^{2}$ in a 48 -well plate (BD Biosciences) and cultured with $1 \mathrm{~mL}$ of either $10 \% \mathrm{FBS}$ (Gibco, Carlsbad, CA), used as a control, or 20\% PRP as described previously [12]. In both cases, DMEM (Life technologies) was added and supplemented with penicillin and streptomycin $(10,000 \mu \mathrm{g} / \mathrm{mL}$; Bioconcept, NH, USA) and 2 units/mL heparin (Liquemin 5000; Roche, Basel, Switzerland). After 24 to $48 \mathrm{~h}$, a plastic-adherent fraction was obtained, and was determined to be ASCs. Cells were cultivated at $37^{\circ} \mathrm{C}$ for 10 days in a standard incubator with $5 \% \mathrm{CO}_{2}$ without changing the culture media. ASC were cultured with PRP of the same patient.

\section{Cell proliferation assessment}

To assess ASC growth, $5000 \mathrm{cell} / \mathrm{cm}^{2}$ were plated in 12-well plates (BD Biosciences) and cultured in DMEM (Life Technologies) with penicillin and streptomycin 10,000 $\mu \mathrm{g} / \mathrm{mL}$ (Bioconcept, NH, USA) and 2 units/mL heparin (Liquemin 5000; Roche, Basel, Switzerland). Cultures were supplemented with $20 \%$ PRP; controls were supplemented with $10 \%$ FBS. The total number of cells under each condition was counted using an image-based cytometer (Tali; Invitrogen). The proliferation rate of ASCs was measured through the expression of PCNA using immunocytochemistry analyses according to standard protocols. Briefly, P1 ASCs seeded at $2500 \mathrm{cell} / \mathrm{cm}^{2}$ with $10 \% \mathrm{FBS}$ or $20 \% \mathrm{PRP}$ for 8 days were fixed with $4 \%$ paraformaldehyde in Dulbecco's PBS for $30 \mathrm{~min}$ at room temperature. After two washes with PBS, fixed cells were blocked in PBS with 1\% FBS for an additional 30 min. Cells were then incubated using rabbit anti-human PCNA antibody (Abcam, Cambridge, UK) and held overnight at $4^{\circ} \mathrm{C}$. After washing with PBS, cells were incubated with an Alexa 555-conjugated anti-rabbit antibody for $2 \mathrm{~h}$ at room temperature. After washing with PBS, cells were incubated for 10 to $15 \mathrm{~min}$ with DAPI for cell nuclei detection and mounted in Fluorosave (Calbiochem). Pictures were taken with a fluorescent plate reader paradigm (6021G). Quantification of DAPI (blue) positive nuclei and PCNA positive cells (red) was performed using metamorph software. Results were expressed as the percent redpositive cells to total DAPI-positive cells per unit of area. The calculated area was the complete picture size at 20x magnification.

\section{Growth Factors and MIF measurement}

To assess the concentration of growth factors, first passage (P0) ASCs were trypsinized and cultured in 20\% PRP for $24 \mathrm{~h}$. The medium was then replaced by $2 \%$ PRP to stop cell signaling. After an additional $24 \mathrm{~h}$, the medium was again replaced with $20 \%$ PRP and kept for 10 days during which time P1 ASCs were collected at $20 \mathrm{~min}, 5$ days, 8 days, and 10 days. After centrifugation for $3 \mathrm{~min}$ at $1500 \mathrm{~g}$, samples were stored at $-20^{\circ} \mathrm{C}$ until use. The amount of TGF $\beta$, PDGF AB, VEGF, and FGF were assessed using enzyme-linked immunosorbent assay (ELISA) kits (Quantikine ${ }^{\circledR}, \mathrm{R} \& D$ Systems, Minneapolis, MN, USA) according to manufacturer's instructions.

To specifically assess the extracellular MIF concentration in the medium, after 10 days' culture, cells were trypsinized and cultured in $10 \%$ FBS or $20 \%$ PRP for $24 \mathrm{~h}$. The medium was then replaced by $2 \%$ FBS or $2 \%$ PRP to stop cell signaling. After an additional $24 \mathrm{~h}$, the medium was again replaced with $10 \%$ FBS or $20 \%$ PRP and kept for 8 days during which time P1 ASCs were collected at $0,1,3,5$, and 8 days. Cells were washed with PBS supplemented with $10 \mathrm{mmol} / \mathrm{L}$ sodium orthovanadate on ice and then lysed prior to protein analysis 
Citation: Atashi F, Serre-Beinier V, Nayernia Z, Pittet-Cuénod B, Modarressi A (2015) Platelet Rich Plasma Promotes Proliferation of Adipose Derived Mesenchymal Stem Cells via Activation of AKT and Smad2 Signaling Pathways. J Stem Cell Res Ther 5: 301. doi:10.4172/21577633.1000301

Page 3 of 10

by western blot analysis in Laemmli sample buffer $(62.5 \mathrm{mmol} / \mathrm{L}$ Tris$\mathrm{HCl}, \mathrm{pH} 7.4,1 \mathrm{mmol} / \mathrm{L}$ EDTA, 2\% (w/v) SDS, 5\% (v/v) glycerol, and $1 \%(\mathrm{v} / \mathrm{v}) 2$-mercaptoethanol). The Duo set ELISA kit (R\&D Systems, Minneapolis, MN, USA) was used according to manufacturer's instructions for measuring MIF secretion levels of ASCs from three patients in day 0 after $20 \mathrm{~min}$, day 3, day 5 and day 8 of culture in media supplemented with $10 \%$ FBS or $20 \%$ PRP.

\section{PDGF receptor (PDGFR), TGF $\beta$ receptor (TGF $\beta R$ )}

The expression of PDGFR and TGF $\beta$ R was determined using immunocytochemistry analyses according to standard protocols as was described in proliferation assessment by PCNA. Rabbit anti-human PDGFR antibody (Abcam, Cambridge, UK) and goat anti-human TGF $\beta$ RII antibody (Santa Cruz, Texas, USA) were used as a primary antibody. Alexa 555-conjugated anti-rabbit antibody and a donkey 555-conjugated anti-goat antibody were used as secondary antibodies. After two washes with PBS, cells were incubated for 10 to $15 \mathrm{~min}$ with DAPI for cell nuclei detection and were mounted in Fluorosave (Calbiochem)

\section{AKT, p-AKT, Erk1/2, p-ERK p/Smad2, GAPDH, cyclinD1, and intracellular MIF analysis}

Adipose-derived mesenchymal stem cells cultured 10 days under various conditions were trypsinized and cultured again in 10\% FBS or $20 \%$ PRP for $24 \mathrm{~h}$ at $2500 \mathrm{cell} / \mathrm{cm}^{2}$. The medium was then replaced by $2 \%$ FBS or $2 \%$ PRP to stop cell signaling prior to investigating the impact of supplement addition on the signaling of ASCs. After $24 \mathrm{~h}$ the medium was again replaced with $10 \%$ FBS or $20 \%$ PRP and kept for 8 days. At $0,1,3,5$, and 8 days, ASCs were lysed and homogenized in Laemmli sample buffer, supplemented with a protease inhibitor cocktail (Roche Diagnostics) and $10 \mathrm{mmol} / \mathrm{L}$ phosphatase inhibitors sodium orthovanadate (Sigma) and sodium pyrophosphate (Sigma). Protein concentrations of all samples were determined using the amido black method as described previously (36). Then, $10 \mu \mathrm{g}$ total proteins were loaded on $8-16 \%$ SDS-PAGE gel. Electrophoresed samples were electroblotted onto polyvinylidene fluoride (PVDF) membranes (Immobilon-P, Millipore) in the presence of $0.01 \%$ (w/v) SDS and $20 \%$ $(\mathrm{v} / \mathrm{v})$ methanol using a constant current of $450 \mathrm{~mA}$ for $1 \mathrm{~h}$. The membranes were saturated for $1 \mathrm{~h}$ at room temperature in a $10 \mathrm{mmol} / \mathrm{L}$ Tris- $\mathrm{HCl}$ buffer (pH 7.4) containing $150 \mathrm{mmol} / \mathrm{L} \mathrm{NaCl}, 0.1 \%$ (v/v) Tween-20 and $5 \% \mathrm{BSA}$, then incubated overnight at $4^{\circ} \mathrm{C}$ with the following antibodies: AKT, phospho-AKT (p-AKT), Erk1/2, phosphor-Erk1/2 (p-ERK), Smad2 and phospho-Smad2 (Cell Signaling Technology, Danvers, MA, USA), GAPDH (Sigma -Aldrich, St. Louis, MO), cyclin D1 (Santa Cruz Biotech, Texas, U.S.A), and anti-endogenous MIF (a gift of Thierry Roger (University of Lausanne). Detection was performed using HRPconjugated secondary antibodies and an enhanced chemiluminescence detection system (Amersham Biosciences). Quantifications were then performed using the ChemiDoc XRS from Bio-Rad Laboratories and Quantity One software (Bio-Rad Laboratories, Hercules, CA, USA).

\section{Statistical analysis}

Differences between pairs were examined for statistical significance using the $t$ test, and values of $p$ less than 0.05 were considered significant. Data are presented as mean \pm SEM.

\section{Results}

\section{ASC proliferation cultured with 20\% PRP}

We previously showed that $20 \%$ autologous PRP increase ASC proliferation more than other concentrations of PRP [12]. Here we showed that a media supplemented with $20 \%$ autologous PRP increased ASC expansion after 10 days of culture. The number of ASCs in 20\% PRP versus $10 \%$ FBS was 14 times greater $(n=14, p<0.001)$. The proliferation rate of ASCs cultured in media supplemented with $10 \%$ FBS or $20 \%$ PRP was assessed over 8 days by analyzing PCNA expression. The expression of PCNA was significantly higher in 20\% PRP compared to $10 \%$ FBS ( $87.68 \%$ vs. $37.07 \%$, respectively) after 3 days' culture (Figure 1A). In 10\% FBS, it increased continuously, while in 20\% PRP it showed a bell-shaped increase, maximizing on day 3. While PCNA expression of ASCs cultured in 10\% FBS increased progressively from day 0 to day 8 (from $28.45 \%$ to $83.48 \%$ ), in $20 \%$ PRP it increased faster and significantly from day 0 to day 3 (from $6.38 \%$ to $87.68 \%$ ) and then decreased significantly from day 5 to day 8 (from $68.03 \%$ to $9.64 \%$ ). Consequently, PCNA expression of ASCs cultured in 20\% PRP was lower on day 8 compared to those cultured in 10\% FBS.

To determine whether the difference in proliferation rate could be a consequence of cyclin D1 expression, its level was analyzed using western blot analysis (Figure 1B). Cyclin D1 expression had a tendency to increase on days 3 and 5 in PRP-treated ASCs.

\section{Proliferation of ASCs cultured in medium supplemented} with $10 \%$ FBS or $20 \%$ PRP.

Adipose-derived mesenchymal stem cells (ASCs) were cultured for 10 days in medium supplemented with $10 \%$ fetal bovine serum (gray bars) or 20\% platelet-rich plasma (black bars). (A) After 20 min, 1 day, 3 days, 5 days, and 8 days, PCNA expression by ASCs was analyzed using immunocytochemistry and quantified using metamorph software. Results were expressed as the percent red-positive cells to total DAPIpositive cells per unit of area. The calculated area is the complete picture size. Magnification is 20x. (B) Cyclin D1 protein was analyzed using western blot analysis. Protein levels were quantified using QuantityOne software and were normalized to GAPDH $n=3$.

\section{Growth factors implicated in ASCs proliferation cultured with $20 \%$ PRP}

To determine the level of several growth factors in the cultured media at days $0,5,8$, and 10 with $20 \%$ PRP, TGF $\beta$, PDGF-AB, FGF, and VEGF levels were measured using ELISA. The PDGF-AB and FGF concentrations in the medium had bell-shaped curves, maximizing on day 5 (Figure $2 \mathrm{~A}$ and $2 \mathrm{~B}$ ). The levels of TGF $\beta$ and VEGF continuously increased from day 0 to day 10 and reached their highest secretion levels on day 10 (Figure 2C and 2D).

\section{Assessment of growth factor concentration in medium supplemented with $20 \%$ PRP}

The secretion of PDGF-AB (A), FGF (B), TGF $\beta$ (C), and VEGF (D) was assessed using ELISA on days 0, 5, 8, and 10. The medium was not changed during the 10 days, $\mathrm{n}=3$.

\section{MIF secretion and expression in $20 \%$ PRP or $10 \%$ FBS}

To investigate the role of MIF on ASC proliferation, we measured the secretion and the expression levels of MIF in 20\% PRP and 10\% FBS. Assessment of MIF concentration levels using ELISA showed a significantly higher MIF concentration in 20\% PRP compared to $10 \%$ FBS on days 0,3 , and 5. Its secretion level in PRP-supplemented medium increased from day 0 to day $3(0.80 \mathrm{ng} / \mathrm{mL}$ to $1.72 \mathrm{ng} / \mathrm{mL}$ respectively), maximizing on day 3 (Figure $3 \mathrm{~A}$ ). In contrast, endogenous MIF expression levels were similar during the culture period and showed 
Citation: Atashi F, Serre-Beinier V, Nayernia Z, Pittet-Cuénod B, Modarressi A (2015) Platelet Rich Plasma Promotes Proliferation of Adipose Derived Mesenchymal Stem Cells via Activation of AKT and Smad2 Signaling Pathways. J Stem Cell Res Ther 5: 301. doi:10.4172/21577633.1000301

A
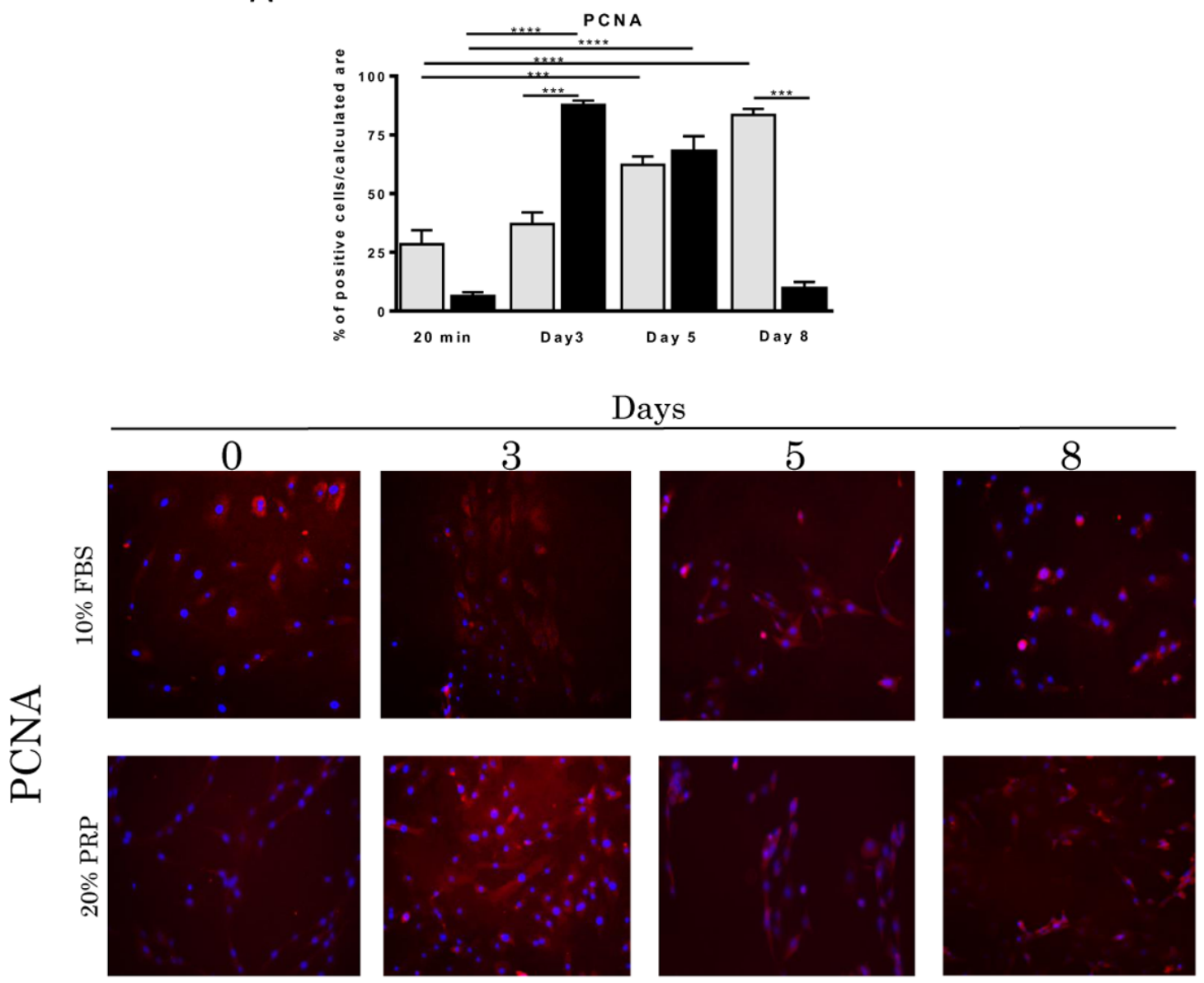

B

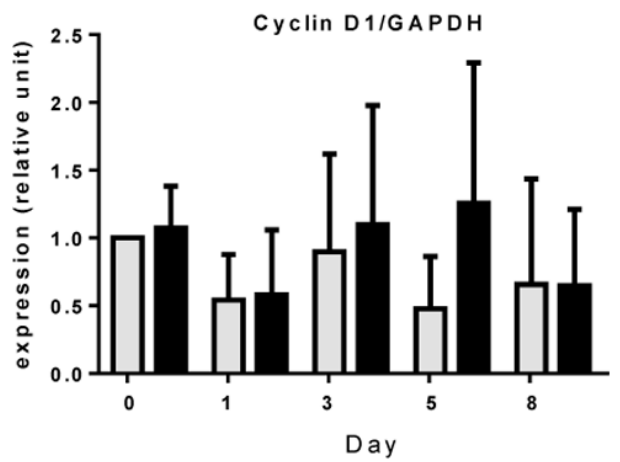

Figure 1: ASC proliferation cultured with $20 \%$ PRP. (black bar) compared to ACS expanded in $10 \%$ FBS $\left(\right.$ gray bar) $\left({ }^{*} p<0.05,{ }^{* *} p<0.01,{ }^{* * *} p<0.005,{ }^{* * * *}\right.$. $\left.p<0.0001\right)$

no significant difference whether cultured with $20 \%$ PRP or $10 \%$ FBS (Figure 3B).

\section{Assessment of MIF secretion and expression}

The secretion of MIF was assessed using ELISA (A) on days 0, 3, 5, and 8 for adipose-derived mesenchymal stem cells cultured with $10 \%$ fetal bovine serum (gray bars) and 20\% platelet-rich plasma (black bars). The medium was not changed. The endogenous concentration of
MIF was assessed using western blot analysis (B) on days $0,1,3,5$, and 8 . The results were then normalized to GAPDH. At each sample point, results were normalized to day $0,10 \%$ FBS. $n=3,{ }^{*} p<0.05$ and ${ }^{* *} p<0.01$.

\section{Assessment of the growth factor receptor expression}

In order to evaluate the impact of PRP and FBS on primary growth factor receptors, immunocytochemical staining was performed. The expression of the PDGF-AB receptor was similar at 
A

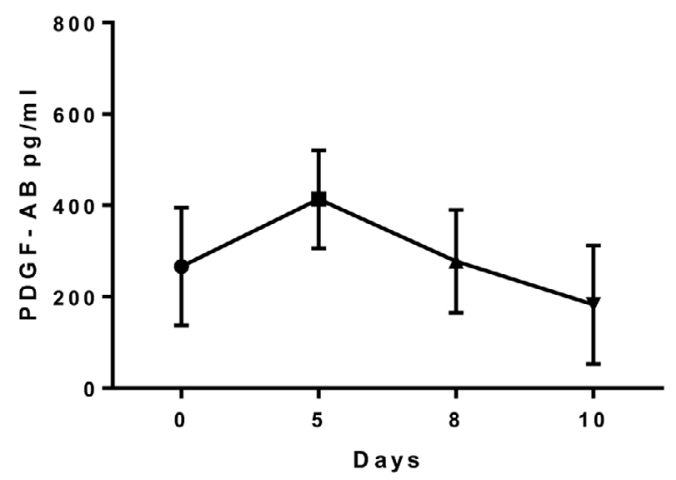

C

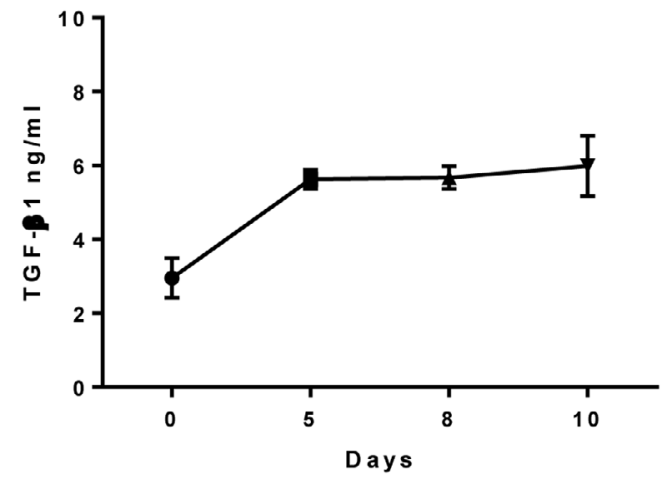

B

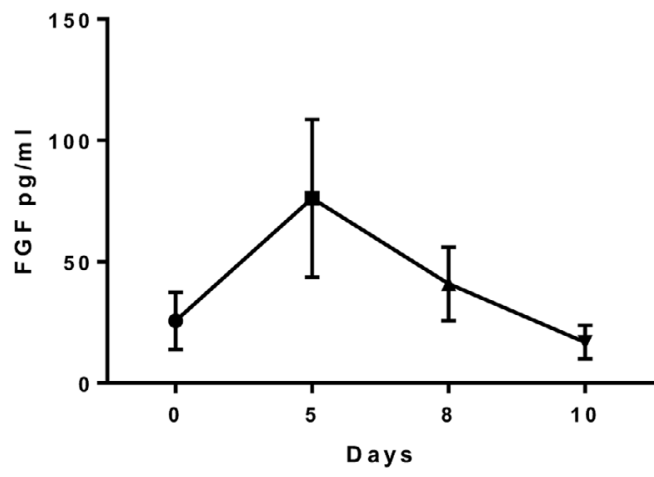

D

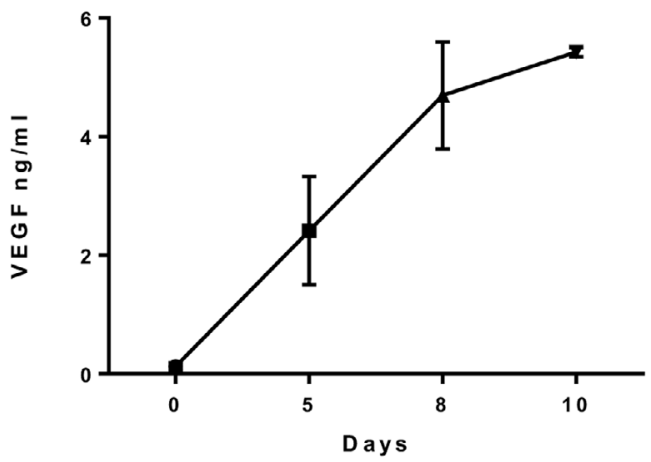

Figure 2: Growth factors implicated in ASCs proliferation cultured with $20 \%$ PRP.

A

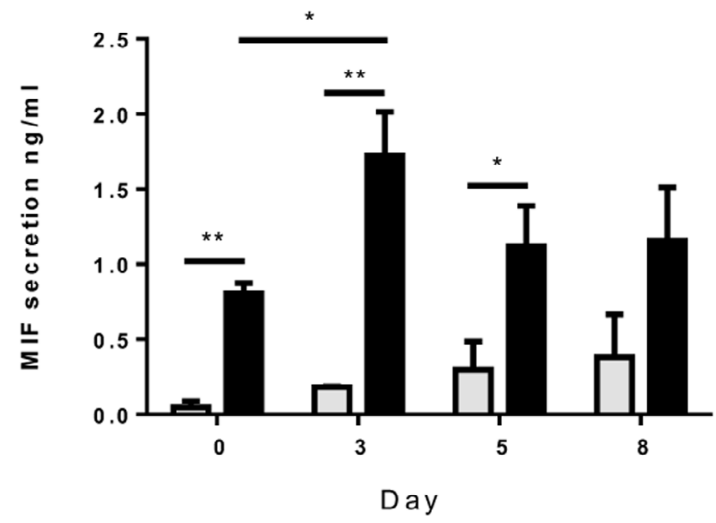

B

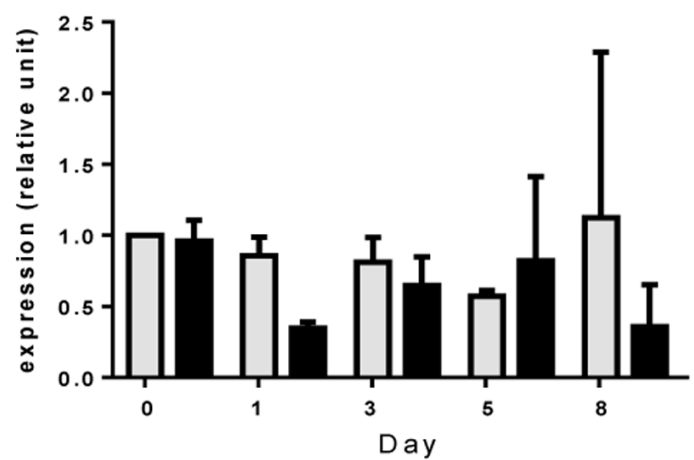

Figure 3: MIF secretion and expression in 20\% PRP (black bar) or 10\% FBS (gray bar).

day 0 (20min) in $20 \%$ PRP and $10 \%$ FBS (Figure $4 \mathrm{~A}$ and $4 \mathrm{C}$ ) and decreased significantly under both conditions on day 8 . However, in $20 \%$ PRP, PDGF-AB receptor expression was significantly lower than in $10 \%$ FBS on day 3 , day 5 and day 8 (Figure $4 \mathrm{~A}$ and $4 \mathrm{C}$ ). Under both conditions, TGF $\beta$ receptor expression increased from day 0 to day 5 and was stable from day 5 to day 8 . However, in 20\% PRP, its expression was significantly lower than in $10 \%$ FBS on day 0 , day 3 and day 5 (Figure 4B and 4D).

\section{PDGFR and TGF $\beta$ R expression in ASCs}

The expression of PDGFR and TGF $\beta$ R were analyzed in adiposederived mesenchymal stem cells cultured in medium supplemented 
Citation: Atashi F, Serre-Beinier V, Nayernia Z, Pittet-Cuénod B, Modarressi A (2015) Platelet Rich Plasma Promotes Proliferation of Adipose Derived Mesenchymal Stem Cells via Activation of AKT and Smad2 Signaling Pathways. J Stem Cell Res Ther 5: 301. doi:10.4172/21577633.1000301

A

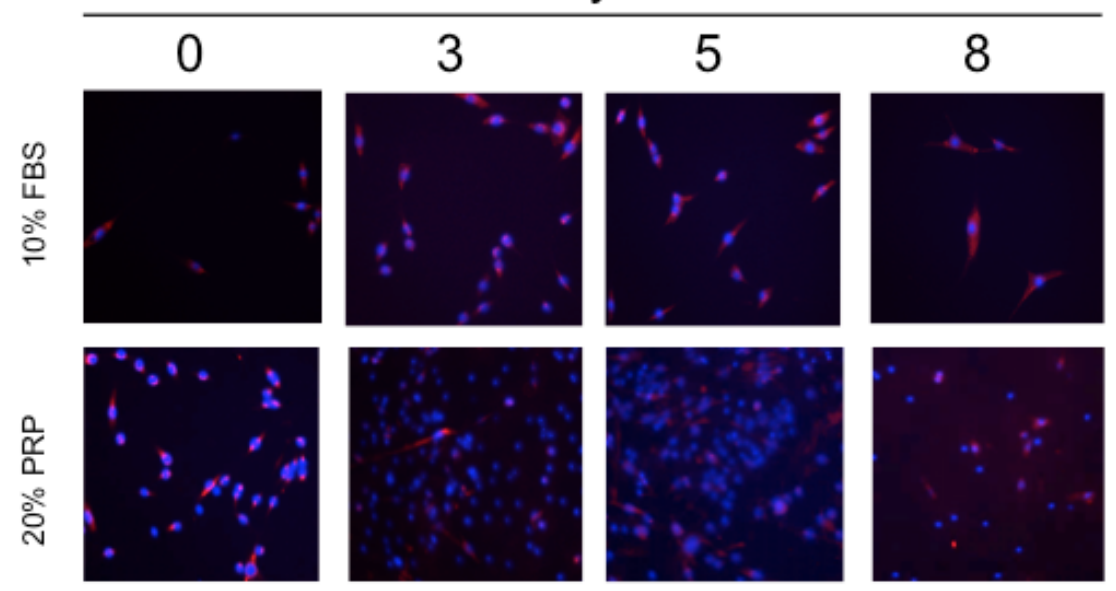

B
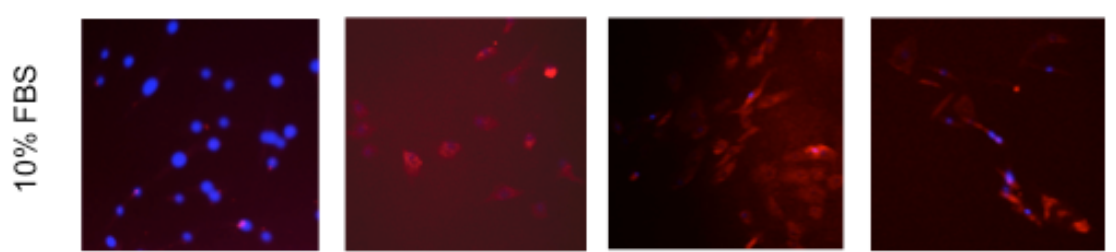

$\stackrel{\substack{1\\}}{\stackrel{一}{\leftarrow}}$
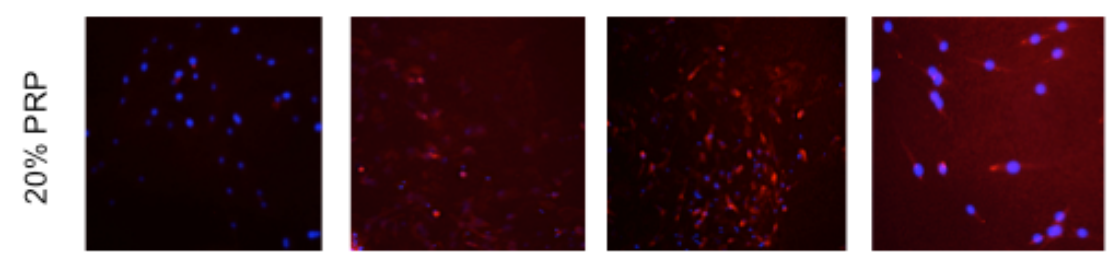

C

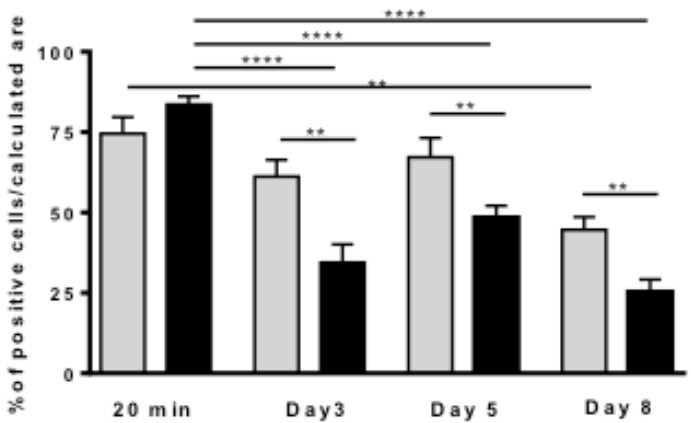

D

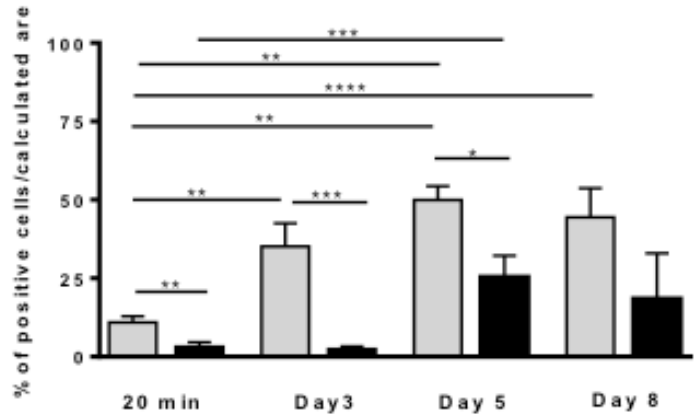

Figure 4: Assessment of the growth factor receptor expression. (A and C: PDGFR, B and D: TGFR) on cells cultured in 10\% FBS (grey bar) compared to those expanded in $20 \%$ PRP. $\left({ }^{*} p<0.05,{ }^{* *} p<0.01,{ }^{* * *} p<0.005,{ }^{* * *} p<0.0001\right)$ 
Citation: Atashi F, Serre-Beinier V, Nayernia Z, Pittet-Cuénod B, Modarressi A (2015) Platelet Rich Plasma Promotes Proliferation of Adipose Derived Mesenchymal Stem Cells via Activation of AKT and Smad2 Signaling Pathways. J Stem Cell Res Ther 5: 301. doi:10.4172/21577633.1000301

Page 7 of 10

with $10 \%$ fetal bovine serum (gray bars) or $20 \%$ platelet-rich plasma (black bars) after 20 min, 3 days, 5 days, and 8 days. They were fixed, permeabilized, and subjected to immunofluorescence staining for the PDGF-AB receptor $(\mathbf{A})$ and the TGF $\beta$ receptor $(\mathbf{B})$. Quantification of DAPI (blue) positive nuclei and PDGF-ABR (C) or TGF $\beta R(\mathbf{D})$ positive cells (red) was performed by metamorph software. Results were expressed as the percent of red-positive cells to total DAPI-positive cells per unit of area. The calculated area is the complete picture size. Magnification is 20x. The medium was not changed through the experiments.

$$
\mathrm{n}=3,{ }^{*} \mathrm{p}<0.05 ;{ }^{* *} \mathrm{p}<0.01 \text {, and }{ }^{* * *} \mathrm{p}<0.001 .
$$

\section{Activated signaling pathways in ASCs cultured in 20\% PRP and $10 \%$ FBS}

The expressions of molecules implicated in the main signaling cascades that are known to be involved in the proliferation of ASCs were analyzed by western blot analysis. Globally activated pAKT expression had a trend to be higher in 20\% PRP than in 10\% FBS at all sample points (Figure 5A). The pERK expression levels in 20\% PRP tended to be higher than in $10 \%$ FBS on days 3,5 , and 8 . In $10 \%$ FBS, it had a tendency to decrease progressively over time, while in $20 \%$ PRP, it increased up to day 3 and then decreased from day 5 to day 8 (Figure 5B). Finally, pSmad2 expression had a tendency to be higher in $20 \%$ PRP than in $10 \%$ FBS at all sample points (Figure 5C). Expression of pSmad 2 did not change from day 0 to day 8 in $10 \%$ FBS, but in $20 \%$
PRP, it decreased from day 0 to day 3 and then increased from day 3 to day 8. Thus, pSmad2 expression level was higher at days 0 and 3 in $20 \%$ PRP than in 10\% FBS and tended to also be higher at days 5 and 8 .

\section{Activated signaling pathways in cultured ASCs}

The expression levels of of pAKT (A), pERK (B), and pSmad2 (C) were assessed for adipose-derived mesenchymal stem cells cultured with $10 \%$ fetal bovine serum (FBS, gray bars) or $20 \%$ platelet-rich plasma (black bars) at $20 \mathrm{~min}, 3$ days, 5 days, and 8 days using western blot analysis. The results were normalized with total AKT, ERK, and Smad2 respectively. The results at all sample points were then normalized to 20 min FBS. $n=3,{ }^{*} \mathrm{p}<0.05$.

\section{Discussion}

Since the 1970s, PRP has been used in the clinic for its regenerative and healing properties [12,36-38]. It has been shown to enhance cell proliferation and differentiation primarily through diverse growth factors secreted by platelets, specifically PDGF-AB, TFG $\beta$, and FGF [39,40]. In our previous study we demonstrated that 20\% PRP stimulated MSC growth and decreased their population doubling time when compared to $10 \% \mathrm{FBS}$, the traditional medium supplement that is widely used now-a-days for cell culture [12]. Though the stimulatory effect of PRP on ASC survival, proliferation, and in vitro expansion has been reported [12,41], the signaling cascades have been poorly investigated.
A

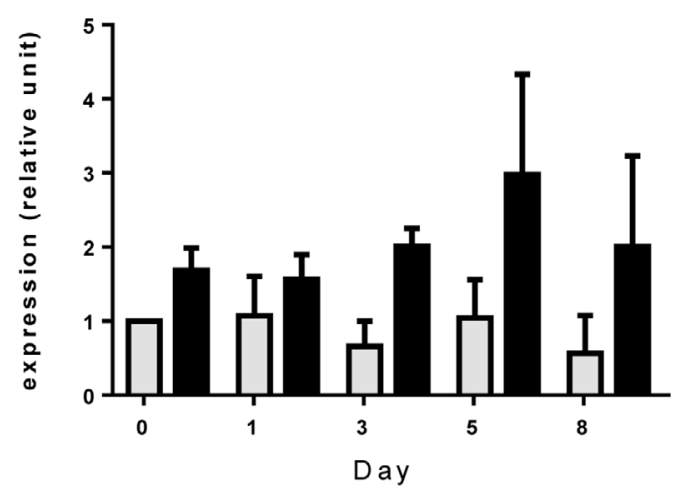

C

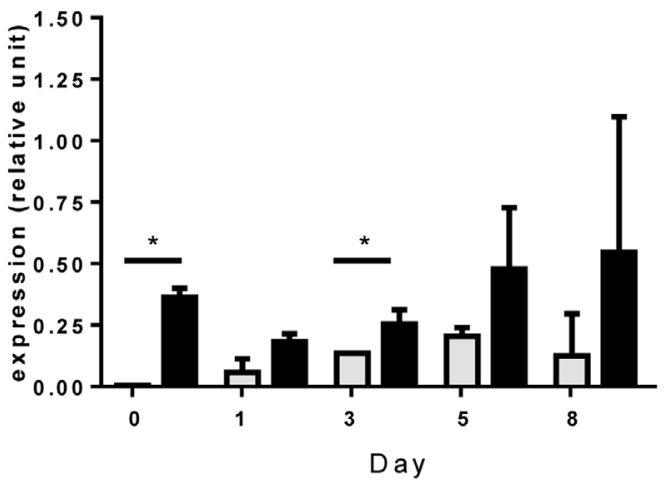

\section{B}

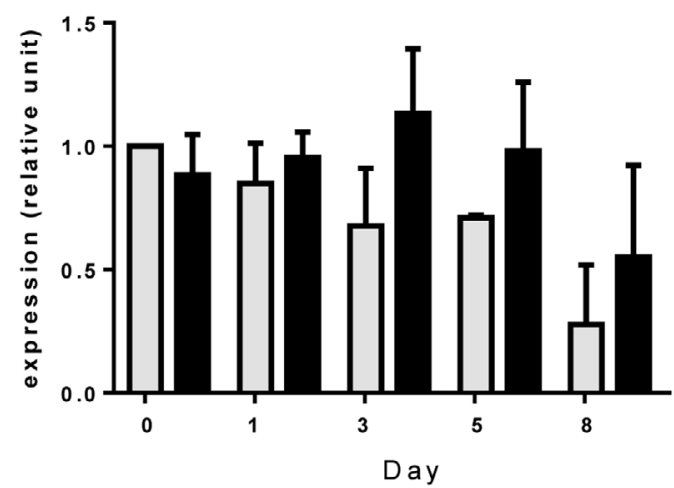

Figure 5: Activated signaling pathways in ASCs cultured in 20\% PRP (black bar) and 10\% FBS ( $\left.{ }^{*} p<0.05\right)$. 
Citation: Atashi F, Serre-Beinier V, Nayernia Z, Pittet-Cuénod B, Modarressi A (2015) Platelet Rich Plasma Promotes Proliferation of Adipose Derived Mesenchymal Stem Cells via Activation of AKT and Smad2 Signaling Pathways. J Stem Cell Res Ther 5: 301. doi:10.4172/21577633.1000301

Page 8 of 10

Through this study, we showed that PRP, compared to FBS, increased ASC proliferation signaling pathways (Figure 6).

\section{Primary signaling pathways regulating ASC proliferation}

Binding of TGF $\beta$ to TGF $\beta$ R initiates Smad2 signaling pathway; Smad2 forms a heterodimer with Smad3, which then triggers the proliferation of adipose-derived mesenchymal stem cells in the nucleus. Binding of TGF $\beta$ and FGF to their cognate receptors triggers the ERK pathway. Phosphorylated ERK then enters the nucleus and activates transcription of cellular proliferation genes. Binding of PDGF, VEGF, FGF, EGF, and MIF to their cognate receptors could initiate the AKT signaling pathway. Phosphorylated AKT prevents the expression of inhibitory proteins of ASC proliferation and activates downstream cell cycle proteins such as cyclin D1.

We observed that the levels of all growth factors studied in the $20 \%$ PRP were highest at day 3 to day 5 after culture initiation, when ASC proliferation was most enhanced. Additionally we observed that MIF concentration in the medium supplemented with PRP was significantly higher than in that supplemented with FBS. The primary signals activated in 20\% PRP were AKT and Smad2.

As seen in our previous studies showing that the cells proliferated more in 20\% PRP, PCNA was expressed significantly more on day 3 in PRP-cultured cells than in FBS-cultured cells. On day 8, the expression of PCNA was significantly lower in PRP-cultured cells. This could be explained by the fact that the culture was already confluent at this time and the cells were not able to proliferate any further. Cyclin D1, a cell cycle progression protein, expressed more in PRP-cultured cells compared to FBS-cultured cells at all sample points, but because of variation between patients, the difference was not statistically significant.

Our results showed that the growth factors are present in the cell culture medium over 8 days.

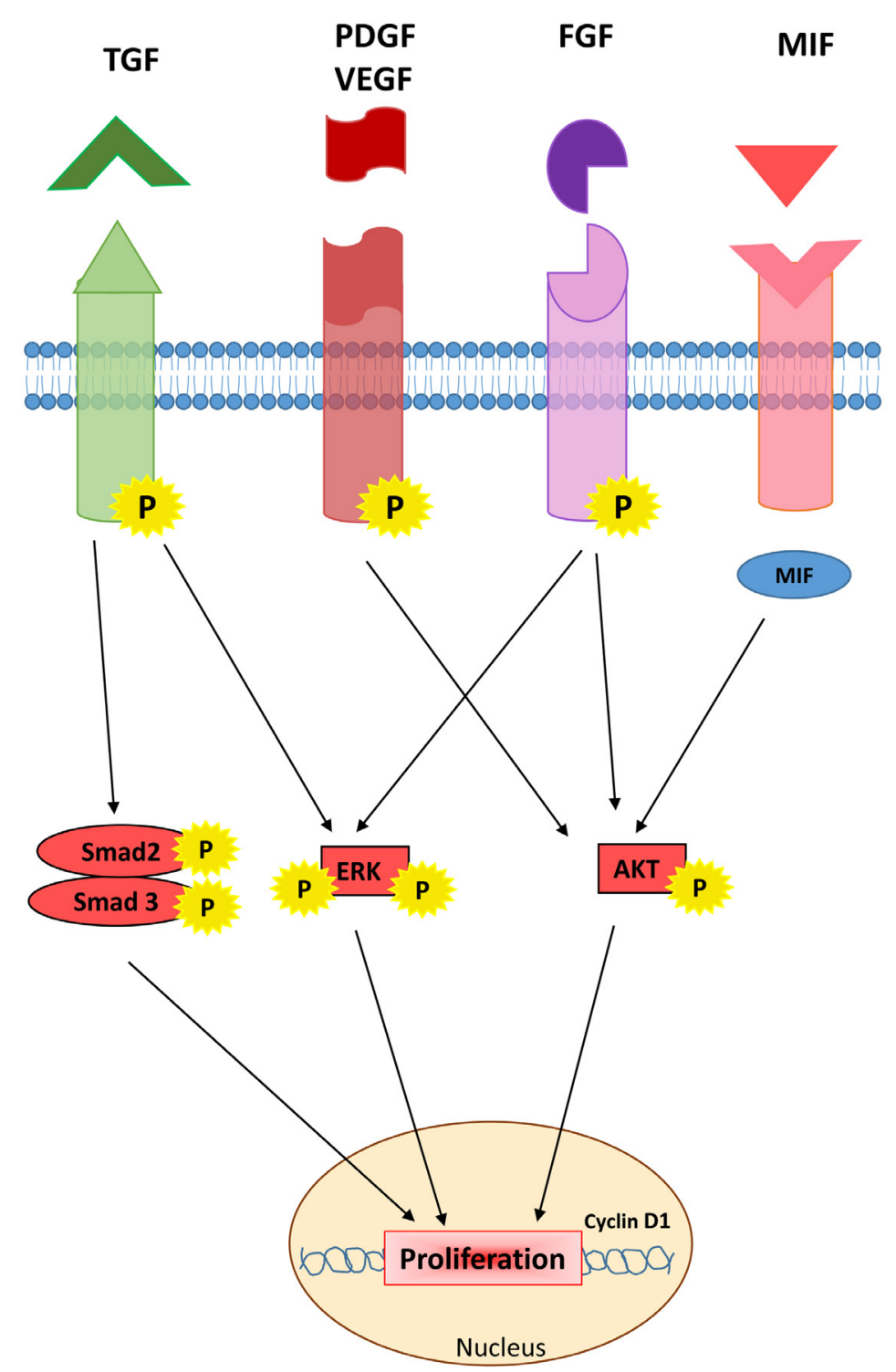

Figure 6: Primary signaling pathways regulating ASC proliferation. 
Citation: Atashi F, Serre-Beinier V, Nayernia Z, Pittet-Cuénod B, Modarressi A (2015) Platelet Rich Plasma Promotes Proliferation of Adipose Derived Mesenchymal Stem Cells via Activation of AKT and Smad2 Signaling Pathways. J Stem Cell Res Ther 5: 301. doi:10.4172/21577633.1000301

Page 9 of 10

It is documented that MIF secreted by ASCs decreases senescence of ASCs by inducing AKT activation/phosphorylation [26]. Moreover, MIF regulates ASC migration [17] and differentiation [25] through autocrine/ paracrine effect. However, to our knowledge, its effect on ASC proliferation has not yet been investigated. We observed that supplementation with PRP, compared to FBS did not change the expression of endogenous MIF by ASCs. However, MIF concentration in 20\% PRP medium was higher than in $10 \%$ FBS medium before adding them to the cell culture (data not shown). This indicates, for the first time to our knowledge, that PRP produces higher concentrations of MIF compared to FBS. Current studies reveal that the proliferation regulatory role of MIF on neural stem/ progenitor cells occurs through activation of AKT signalling pathways $[21,22]$. We demonstrated that AKT signaling is increased in $20 \% \mathrm{PRP}$, and we also assumed that exogenous MIF produced by PRP could play a positive role in proliferation of ASCs.

The effects of PDGF-AB, FGF, TGF $\beta$, and VEGF on ASC proliferation may be controlled through binding to their respective receptors. But recently it has been documented that there is no VEGFR expression in ASCs [12]. Peng et al. reported that VEGF can directly signal through PDGFR [41]. Interestingly, we found that TGF $\beta$ R and PDGFR showed lower expression in PRP than in FBS. It has been reported that the proliferation of fibroblasts after exposure to mitogen is controlled through the down-regulation of growth factor receptors [4244]. According to this concept, we can suppose that high concentrations of PDGF-AB, VEGF, and TGF $\beta$ in PRP-supplemented media could also provoke a negative feedback loop on ASC receptors.

The binding of various growth factors to their cell surface receptors activates several signaling cascades leading to an intracellular response. Currently, most studies that elucidated signalling pathways of ASC proliferation pointed to the AKT pathway $[29,41]$. Through this study, the expression of AKT and Smad2 showed a tendency to increase and ERK to decrease at several sample points under both culture conditions. The data could be statistically insignificant because of variations in the growth factor secretion levels in PRP between patients and because of variations in protein expression between patients. Compared to FBS, we observed a higher activation of the AKT pathway in 20\% PRP, particularly at day 3 , the period when the ASC proliferation rate was the highest. We also observed a higher activation of the Smad 2 pathway in $20 \%$ PRP compared to FBS. We observed similar expression patterns between PDGF-AB, FGF, and pAKT, and between TGF $\beta$ and pSmad2. These results could suggest that binding of PDGF-AB, VEGF, and FGF to their specific receptors stimulates the AKT signaling pathway, while binding of TGF $\beta$ to TGF $\beta$ receptor stimulates the pSmad2 pathway, as proposed by Rodrigues et al. [33]. Activation of the AKT/ Smad2 pathways resulted in enhancing proliferation of ASCs through increased expression of cell cycle progression proteins such as cyclin D1. As reported by Dalton et al. [30], we think that PDGF-AB, FGF, and TGF $\beta$ are all required to activate the AKT signaling pathway and therefore ASC proliferation. It is noteworthy to mention that in agreement with Peng et al. [41], who showed that AKT is the main signaling cascade in ASC proliferation; our results indicate that PRP induces proliferation of ASCs mainly through PDGFR/AKT and also through TGF $\beta$ R/Smad2 signaling pathway. Activation of the EKR1/2 signaling pathway was not significantly different between 20\% PRP and $10 \%$ FBS. As found by Gharibi et al. [29], our observations indicate that ERK could have a negligible effect on ASC proliferation. In early studies, ERK was shown to be the dominant factor responsible for ASC proliferation in the presence of PDGF-AB [45]. However, recently Ding et al. [46], demonstrated that PDGFR inhibitors do not change the phosphorylation/activation level of ERK.
In summary, based on our results, we postulate that substituting FBS with PRP would not only be safe and biocompatible, but it would also activate many signalling pathways by secreting its cocktail of growth factors. Modulation of these pathways could be a promising approach to safely and efficiently boost the proliferation of ASCs in vitro and in the clinic. Further studies would be necessary to characterize the exact effect of MIF on ASC proliferation and migration using MIF inhibitors and recombinant MIF.

\section{Acknowledgement}

The authors would like to thank Mr. Romain Baechler for his technical assistance.

\section{Source of Funding}

This study was supported by the Swiss National Science Foundation (Grant \#310030-120751 B Pittet-Cuénod).

\section{Conflict of Interest}

The Regen BCT tubes were generously provided by Regen Lab.

\section{References}

1. Tsuji W, Rubin JP, Marra KG (2014) Adipose-derived stem cells: Implications in tissue regeneration. World J Stem Cells 6: 312-321. [PubMed]

2. Reiser J, Zhang XY, Hemenway CS, Mondal D, Pradhan L, et al. (2005) Potential of mesenchymal stem cells in gene therapy approaches for inherited and acquired diseases. Expert Opin Biol Ther 5: 1571-1584. [PubMed]

3. Schaffler A, Buchler C (2007) Concise review: adipose tissue-derived stromal cells--basic and clinical implications for novel cell-based therapies. Stem Cells 25: 818-827. [PubMed]

4. Kopen GC, Prockop DJ, Phinney DG (1999) Marrow stromal cells migrate throughout forebrain and cerebellum, and they differentiate into astrocytes afte injection into neonatal mouse brains. Proc Natl Acad Sci USA 96: 10711-10716. [PubMed]

5. Toma C, Pittenger MF, Cahill KS, Byrne BJ, Kessler PD (2002) Human mesenchymal stem cells differentiate to a cardiomyocyte phenotype in the adult murine heart. Circulation 105: 93-98. [PubMed]

6. Ghorbani A, Jalali SA, Varedi M (2014) Isolation of adipose tissue mesenchymal stem cells without tissue destruction: a non-enzymatic method. Tissue Cell 46 54-58. [PubMed]

7. Geissler S, Textor M, Schmidt-Bleek K, Klein O, Thiele M, et al. (2013) In serum veritas-in serum sanitas? Cell non-autonomous aging compromises differentiation and survival of mesenchymal stromal cells via the oxidative stress pathway. Cell Death Dis 4: e970. [PubMed]

8. Schallmoser K, Bartmann C, Rohde E, Reinisch A, Kashofer K, et al. (2007) Human platelet lysate can replace fetal bovine serum for clinical-scale expansion of functional mesenchymal stromal cells. Transfusion 47: 14361346. [PubMed]

9. Phadnis SM, Joglekar MV, Venkateshan V, Ghaskadbi SM, Hardikar AA, et al. (2006) Human umbilical cord blood serum promotes growth, proliferation, as well as differentiation of human bone marrow-derived progenitor cells. In Vitro Cell Dev Biol Anim 42: 283-286. [PubMed]

10. Selvaggi TA, Walker RE, Fleisher TA (1997) Development of antibodies to feta calf serum with arthus-like reactions in human immunodeficiency virus-infected patients given syngeneic lymphocyte infusions. Blood 89: 776-779. [PubMed]

11. Verrier S, Meury TR, Kupcsik L, Heini P, Stoll T, et al. (2010) Platelet-released supernatant induces osteoblastic differentiation of human mesenchymal stem cells: potential role of BMP-2. Eur Cell Mater 20: 403-414. [PubMed]

12. Atashi F, Jaconi ME, Pittet-Cuenod B, Modarressi A (2014) Autologous Platelet-Rich Plasma: A Biological Supplement to Enhance Adipose-Derived Mesenchymal Stem Cell Expansion. Tissue Eng Part C Methods 21: 253-262. [PubMed]

13. Rendu F, Brohard-Bohn B (2001) The platelet release reaction: granules' constituents, secretion and functions. Platelets 12: 261-273. [PubMed]

14. Mitchell RA, Bucala R (2000) Tumor growth-promoting properties of macrophage migration inhibitory factor (MIF). Semin Cancer Biol 10: 359-366. [PubMed] 
Citation: Atashi F, Serre-Beinier V, Nayernia Z, Pittet-Cuénod B, Modarressi A (2015) Platelet Rich Plasma Promotes Proliferation of Adipose Derived Mesenchymal Stem Cells via Activation of AKT and Smad2 Signaling Pathways. J Stem Cell Res Ther 5: 301. doi:10.4172/21577633.1000301

Page 10 of 10

15. Barrett JT (1976) Basic immunology and its medical application. C. V. Mosby, Saint Louis.

16. Serre-Beinier V, Toso C, Morel P, Gonelle-Gispert C, Veyrat-Durebex C, et al. (2010) Macrophage migration inhibitory factor deficiency leads to agedependent impairment of glucose homeostasis in mice. J Endocrinol 206: 297306. [PubMed]

17. Fischer-Valuck BW, Barrilleaux BL, Phinney DG, Russell KC, Prockop DJ, et al. (2010) Migratory response of mesenchymal stem cells to macrophage migration inhibitory factor and its antagonist as a function of colony-forming efficiency. Biotechnology letters 32: 19-27. [PubMed]

18. Hwang JH, Shim SS, Seok OS, Lee HY, Woo SK, et al. (2009) Comparison of cytokine expression in mesenchymal stem cells from human placenta, cord blood, and bone marrow. J Korean Med Sci 24: 547-554. [PubMed]

19. Strussmann T, Tillmann S, Wirtz T, Bucala $R$, von Hundelshausen $P$, et al. (2013) Platelets are a previously unrecognised source of MIF. Thromb Haemost 110: 1004-1013. [PubMed]

20. Sun HW, Bernhagen J, Bucala R, Lolis E (1996) Crystal structure at 2.6-A resolution of human macrophage migration inhibitory factor. Proc Natl Acad Sci USA 93: 5191-5196. [PubMed]

21. Zhang B, Shen M, Xu M, Liu LL, Luo Y, et al. (2012) Role of macrophage migration inhibitory factor in the proliferation of smooth muscle cell in pulmonary hypertension. Mediators of inflammation 2012: 840737. [PubMed]

22. Ohta S, Misawa A, Fukaya R, Inoue S, Kanemura Y, et al. (2012) Macrophage migration inhibitory factor (MIF) promotes cell survival and proliferation of neural stem/progenitor cells. J Cell Sci 125: 3210-3220. [PubMed]

23. Wen Y, Li GW, Bekhor I (1996) Lens epithelial cell mRNA. III. Elevated expression of macrophage migration inhibitory factor mRNA in galactose cataracts. Curr Eye Res 15: 125-130. [PubMed]

24. Lue H, Thiele M, Franz J, Dahl E, Speckgens S, et al. (2007) Macrophage migration inhibitory factor (MIF) promotes cell survival by activation of the Akt pathway and role for CSN5/JAB1 in the control of autocrine MIF activity. Oncogene 26: 5046-5059. [PubMed]

25. Ikeda D, Sakaue S, Kamigaki M, Ohira H, Itoh N, et al. (2008) Knockdown of macrophage migration inhibitory factor disrupts adipogenesis in 3T3-L1 cells. Endocrinology 149: 6037-6042. [PubMed]

26. Palumbo S, Tsai TL, Li WJ (2014) Macrophage migration inhibitory factor regulates AKT signaling in hypoxic culture to modulate senescence of human mesenchymal stem cells. Stem Cells Dev 23: 852-865. [PubMed]

27. Casella I, Feccia T, Chelucci C, Samoggia P, Castelli G, et al. (2003) Autocrineparacrine VEGF loops potentiate the maturation of megakaryocytic precursors through Flt1 receptor. Blood 101: 1316-1323. [PubMed]

28. Gerber HP, Malik AK, Solar GP, Sherman D, Liang XH, et al. (2002) VEGF regulates haematopoietic stem cell survival by an internal autocrine loop mechanism. Nature 417: 954-958. [PubMed]

29. Gharibi B, Ghuman MS, Hughes FJ (2012) Akt- and Erk-mediated regulation of proliferation and differentiation during PDGFRbeta-induced MSC self-renewal. J Cell Mol Med 16: 2789-2801. [PubMed]

30. Dalton S (2013) Signaling networks in human pluripotent stem cells. Curr Opin Cell Biol 25: 241-246. [PubMed]

31. Leng L, Metz CN, Fang Y, Xu J, Donnelly S, et al. (2003) MIF signal transduction initiated by binding to CD74. J Exp Med 197: 1467-1476. [PubMed]

32. Choi SC, Kim SJ, Choi JH, Park CY, Shim WJ, et al. (2008) Fibroblast growth factor-2 and -4 promote the proliferation of bone marrow mesenchymal stem cells by the activation of the PI3K-Akt and ERK1/2 signaling pathways. Stem Cells Dev 17: 725-736. [PubMed]
33. Rodrigues M, Griffith LG, Wells A (2010) Growth factor regulation of proliferation and survival of multipotential stromal cells. Stem Cell Res Ther 1: 32. [PubMed]

34. Strzalka W, Ziemienowicz A (2011) Proliferating cell nuclear antigen (PCNA): a key factor in DNA replication and cell cycle regulation. Ann Bot 107: 1127-1140. [PubMed]

35. Coleman SR (1995) Long-term survival of fat transplants: controlled demonstrations. Aesthetic Plast Surg 19: 421-425. [PubMed]

36. Schaffner W, Weissmann C (1973) A rapid, sensitive, and specific method for the determination of protein in dilute solution. Anal Biochem 56: 502-514. [PubMed]

37. Mei-Dan O, Laver L, Nyska M, Mann G (2011) [Platelet rich plasma--a new biotechnology for treatment of sports injuries]. Harefuah 150: 453-457. [PubMed]

38. Scherer SS, Tobalem M, Vigato E, Heit Y, Modarressi A, et al. (2012) Nonactivated versus thrombin-activated platelets on wound healing and fibroblast-to-myofibroblast differentiation in vivo and in vitro. Plast Reconstr Surg 129: 46e-54e. [PubMed]

39. Gao F, Wang JX, Han Y (2009) [Research advance on application of plateletrich plasma in wound repair -- review]. Zhongguo Shi Yan Xue Ye Xue Za Zh 17: 840-843. [PubMed]

40. Ng F, Boucher S, Koh S, Sastry KS, Chase L, et al. (2008) PDGF, TGF-beta and FGF signaling is important for differentiation and growth of mesenchymal stem cells (MSCs): transcriptional profiling can identify markers and signaling pathways important in differentiation of MSCs into adipogenic, chondrogenic and osteogenic lineages. Blood 112: 295-307. [PubMed]

41. Peng $Y$, Huang $S$, Wu $Y$, Cheng $B$, Nie $X$, et al (2013) Platelet rich plasma clot releasate preconditioning induced PI3K/AKT/NFkappaB signaling enhances survival and regenerative function of rat bone marrow mesenchymal stem cells in hostile microenvironments. Stem Cells Dev 22: 3236-3251. [PubMed]

42. Oster SK, Marhin WW, Asker C, Facchini LM, Dion PA, et al. (2000) Myc is an essential negative regulator of platelet-derived growth factor beta receptor expression. Mol Cell Biol 20: 6768-6778. [PubMed]

43. Nilsson J, Thyberg J, Heldin CH, Westermark B, Wasteson A (1983) Surface binding and internalization of platelet-derived growth factor in human fibroblasts. Proc Natl Acad Sci USA 80: 5592-5596. [PubMed]

44. Rosenfeld ME, Bowen-Pope DF, Ross R (1984) Platelet-derived growth factor: morphologic and biochemical studies of binding, internalization, and degradation. J Cell Physiol 121: 263-274. [PubMed]

45. Tamama K, Fan VH, Griffith LG, Blair HC, Wells A (2006) Epidermal growth factor as a candidate for ex vivo expansion of bone marrow-derived mesenchymal stem cells. Stem cells 24: 686-695. [PubMed]

46. Ding W, Knox TR, Tschumper RC, Wu W, Schwager SM, et al. (2010) Plateletderived growth factor (PDGF)-PDGF receptor interaction activates bone marrow-derived mesenchymal stromal cells derived from chronic lymphocytic leukemia: implications for an angiogenic switch. Blood 116: 2984-2993. [PubMed] 